\title{
Study of Hearing Status in COVID-19 Patients: A Multicentered Review
}

\author{
Subash Bhatta ${ }^{1}$ (D) Santosh Sharma ${ }^{2} \cdot$ Dibya Sharma $^{1} \cdot$ Leison Maharjan $^{3} \cdot$

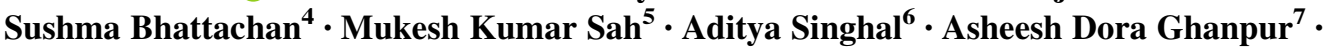 \\ Dushyanth Ganesuni ${ }^{8}$
}

Received: 26 May 2021 / Accepted: 20 June 2021 / Published online: 12 July 2021

(C) Association of Otolaryngologists of India 2021

\begin{abstract}
To evaluate the hearing status of COVID-19 patients and compare with control group. Prospective study carried out in 9 institutes. The pure tone audiogram and impedance audiometry of COVID-19 patients performed initially and at 3 months follow up. The control group consisted COVID-19 negative individuals with no history of ear related diseases. The average of air and bone conduction threshold (AC and $\mathrm{BC}$ ) were compared between the COVID-19 patients and control group using independent t-test with a $p$ value of less than 0.05 considered significant. Total of 331 patients, age $32 \pm 4.3$ years, $66.7 \%$ males and $33.3 \%$ females were included in the study. There were 80 individuals in the control group. Aural symptoms were, tinnitus in $1.8 \%$, aural fullness in $1.4 \%$, hearing loss in $3.9 \%$, and ear ache in $1.8 \%$ were present initially, resolved at 3 months follow up. The impedance audiometry demonstrated type B and type C curve in $5.1 \%$ and $1.15 \%$ ears, and out of these $64.7 \%$ and $40 \%$ improved at 3 months follow up respectively. No significant difference observed between the average AC and $\mathrm{BC}$ of the COVID-19 patients and control group. The
\end{abstract}

Subash Bhatta

2042subase@gmail.com

Indira Gandhi Memorial Hospital, Male', Maldives

2 Devdaha Medical College, Butwal, Nepal

3 Patan Academy of Health Sciences, Patan, Nepal

4 Hospital for Advanced Medicine and Surgery, Kathmandu, Nepal

5 National Medical College, Birgunj, Nepal

6 Rajshree Medical Research Institute, Bareilly, India

7 Osmania Medical College, Hyderabad, India

8 Continental Hospital and Research Center, Hyderabad, India
COVID-19 infection may present with aural symptoms; however, it was concluded that there was no significant difference in the hearing status of the COVID-19 positive patients in comparison to the control group. The presence of some changes in the normal functioning of the eustachian tube and middle ear in the COVID-19 infection was also highlighted.

Keywords COVID-19 · Hearing · Pure tone audiometry . Impedance audiometry

\section{Introduction}

The corona virus disease 2019 (COVID-19) is caused by severe acute respiratory syndrome coronavirus 2 (SARSCoV-2) [1-4]. The disease was declared pandemic by the WHO on March 11, 2020 [5]. Transmission of the COVID19 occurs through contact of the infected droplets to the oral, nasal and eye mucous membrane [6-8]. COVID-19 infection occurs with varying degree of severity affecting multiple organ system of the body such as the respiratory, neurological, and gastrointestinal systems [9-12]. This has resulted in a vast diversity in the presentation of the COVID-19 disease.

The various studies in the literature have described presentation of the COVID-19 infection without any firm evidence suggesting any one of the presentations as the pathognomic for COVID-19 infection [3, 4, 9, 10, 13-16]. The most commonly encountered presenting features are cough, fever, sore throat, head ache, difficulty in breathing, olfactory and gustatory disturbance, diarrhea, myalgia, nasal obstruction, fatigue, rhinorrhea, expectoration and post nasal drip. 
Hearing loss caused by the viral infection has been previously reported by several studies in the literature [17-20]. However, there is scarce literature describing the hearing loss in association with the COVID-19 infection $[2,21-23]$. The present study evaluates the hearing status of the COVID-19 patients from the 9 institutes of 3 different countries. This is by far one of the largest studies in the literature that has evaluated the hearing status of the COVID-19 patients.

\section{Material and Methods}

This was the prospective study conducted from 01/07/2020 to 30/04/2021. It was simultaneously carried out in 8 different institutes; Indira Gandhi memorial hospital (IGMH) (Male', Maldives), Patan academy of health sciences (PAHS) (Patan, Nepal), Hospital for advanced medicine and surgery (HAMS) (Kathmandu, Nepal), Devdaha Medical college (DMC) (Butwal, Nepal), National Medical college (NMC) (Birgunj, Nepal), Osmania Medical college (OMC) (Hyderabad, India), Continental hospital and research center (CHRC) (Hyderabad, India) and Rajshree Medical Research Institute (RMRI) (Bareily, India). The ethical approval for the study was obtained from the institutional ethical committees of the respective institutes.

The patients positive for the COVID-19 infection as confirmed by the reverse transcriptase polymerase chain reaction (RT PCR) were included in the study. Patients of all genders and age, between 14 and 45 years, without any previously documented ear and hearing complaints were included in the study. The patients prescribed with any medication for the COVID-19 infection were excluded from the study. The detail history and examination of each and every patient was evaluated. The history related to ear was elaborated. The patients were specifically asked about the aural symptoms such as hearing loss, aural fullness, tinnitus, ear ache, and ear discharge, if any. The symptoms with duration of onset within 14 days of the RT PCR test were only considered. The patient's hearing status was further evaluated by performing, pure tone audiogram (PTA) and impedance audiometry. The hearing evaluations were performed initially, at the time when RT PCR was positive for COVID-19 infection, and then at 3 months follow up. The patients were inquired about the status of the aural symptoms also at the 3 months follow up. The findings were categorized separately into group 1 and group 2 findings, for initial and 3 months follow up, respectively. The bone conduction $(\mathrm{BC})$ and air conduction (AC) threshold average were calculated separately at the frequencies of $1000 \mathrm{~Hz}, 2000 \mathrm{~Hz}, 3000 \mathrm{~Hz}$ and $4000 \mathrm{~Hz}$ (low frequency). The $\mathrm{BC}$ and $\mathrm{AC}$ average was also calculated separately at $6000 \mathrm{~Hz}$ and $8000 \mathrm{~Hz}$ (high frequency). The impedance audiometry was recorded as A curve, $\mathrm{B}$ curve, As curve, Ad curve and $\mathrm{C}$ curve for each and every patient.

The control group comprised 10 volunteers from each institute who tested RT PCR negative for COVID-19 infection, of comparable age and did not have any ear or hearing problems. PTA and impedance audiometry were performed in 10 individuals in the same way as done in the COVID-19 positive patients. The PTA and impedance audiometry findings were tabulated according to the number of ears for both COVID-19 patients and the control group.

The COVID-19 positive patients and the control individuals were briefed in detail about the research article in their respective local language. Participation in the study was only considered after the signed written consent was obtained from the subjects, and the participants were assured about the confidentiality of the information they provided. The PTA and impedance audiometry were performed free of cost for all the subjects included in the study, undertaking the full precautions against the spread of COVID-19 infection.

Analysis software MedCalc $($, Version 19.2.6, was used for data analysis. An independent t-test was performed to evaluate the significance of the difference in average mean ( $\mathrm{AC}$ and $\mathrm{BC}$ at both low and high frequency) between the group 1 against the control group, and the group 2 against the control group, respectively. The $p$ value of less than 0.05 was considered to be significant. The impedance audiometry was analyzed and compared as the percentage of total.

\section{Results}

A total of 331 COVID-19 positive patients were included in the study; with distribution from each institute as shown in Figs. 1, 2, 3 and 4. The average age of the patients was $32 \pm 4.3$ years (18-38 years). There were 220 (66.4\%) males and 111/331 (33.6\%) female patients. The total number of individuals included in control group was 80 (10 individuals from each institute). The average age of the control group was $28 \pm 3.6$ years (22-35 years), with $57 / 80(71.2 \%)$ males and 23/80 (28.2\%) females. The average duration of first PTA and impedance audiometry was $3.1 \pm 1.4$ days from the day, RT PCR was positive for COVID-19. Similarly, the average duration of second PTA and impedance audiometry was $103.4 \pm 10.8$ days from the first PTA and impedance audiometry. The distribution of the patients on the basis of various aural symptoms is as shown in Fig. 1. The aural symptoms were, tinnitus in $6 / 331(1.8 \%$ ), aural fullness in 38/331 (11.4\%), hearing loss in $12 / 331$ (3. 9\%), and ear ache in $6 / 331(1.8 \%)$, as 
Fig. 1 Distribution of the patients on the basis of aural symptoms. Abbreviations: hospital, PAHS Patan academy of health sciences, HAMS and surgery, $D M C$ Devdaha Medical college, $N M C$ National Medical college, OMC Osmania Medical college, $C H R C$ Continental hospital and research center, RMRI Rajshree Medical Research Institute $I G M H$ Indira Gandhi memorial Hospital for advanced medicine

14

12

10

8

\begin{tabular}{cccccccc}
\hline IGMH & PAHS & HAMS & NMC & DMC & OMC & CHRC & RMRI \\
$(n=48)$ & $(n=47)$ & $\begin{array}{c}\text { (n=18) } \\
(n=53)\end{array}$ & $\begin{array}{c}(n=31) \\
(n=83)\end{array}$ & $\begin{array}{c}(n=23) \\
(n=28)\end{array}$
\end{tabular}

30

Fig. 2 Average $\mathrm{AC}$ and $\mathrm{BC}$ of group 1 and 2 along with the control group for low frequency with their SD. Note: 'n' signifies total number of ears.

Abbreviations: $A C$ Air

conduction, $B C$ Bone

conduction, $S D$ standard

deviation, IGMH Indira Gandhi memorial hospital, PAHS Patan academy of health sciences, HAMS Hospital for advanced medicine and surgery, $D M C$ Devdaha Medical college, NMC National Medical college, $O M C$ Osmania Medical college, CHRC Continental hospital and research center, RMRI Rajshree Medical Research Institute

Fig. 3 Average AC and BC of group 1 and 2 along with the control group for high frequency with their SD. Note: ' $n$ ' signifies total number of ears. Abbreviations: $A C$ Air conduction, $B C$ Bone conduction, $S D$ standard deviation, IGMH Indira Gandhi memorial hospital, PAHS Patan academy of health sciences, HAMS Hospital for advanced medicine and surgery, $D M C$ Devdaha Medical college, $N M C$ National Medical college, $O M C$ Osmania Medical college, CHRC Continental hospital and research center, RMRI Rajshree Medical Research Institute

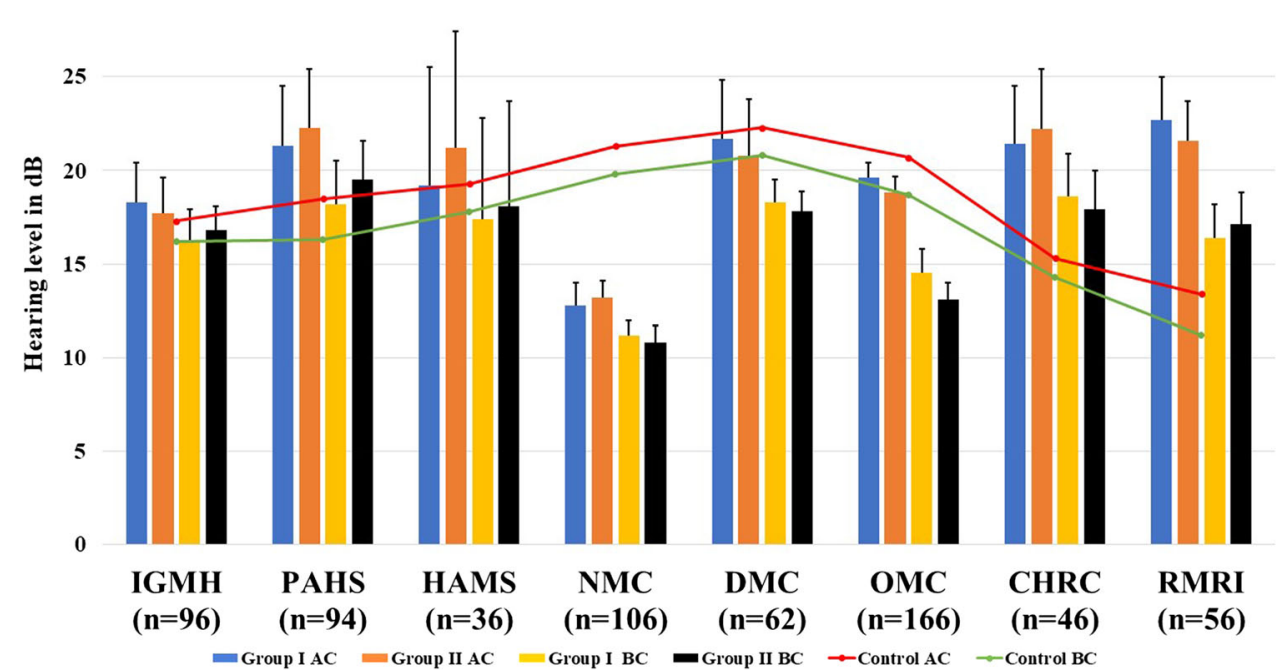

30

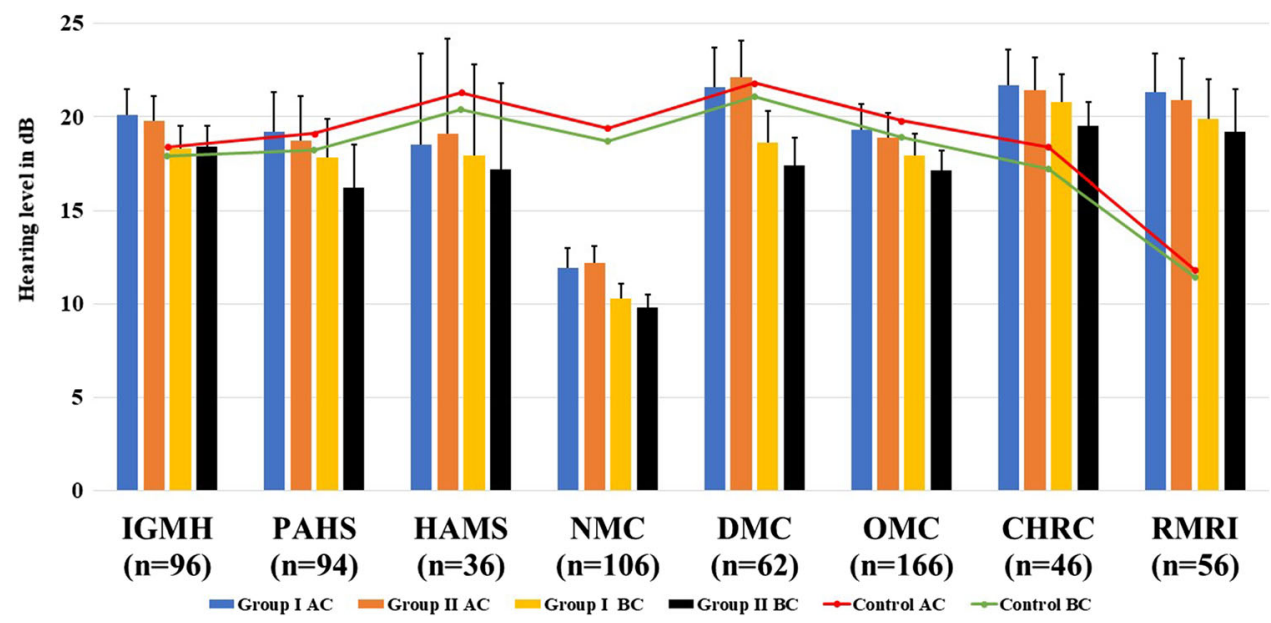


Fig. 4 Impedance audiometry of the patients in group 1 and group 2. Note: 'n' signifies total number of ears. Abbreviations: $I G M H$ Indira Gandhi memorial hospital, PAHS Patan academy of health sciences, HAMS Hospital for advanced medicine and surgery, $D M C$ Devdaha Medical college, $N M C$ National Medical college, OMC Osmania Medical college, CHRC Continental hospital and research center, RMRI Rajshree Medical Research Institute

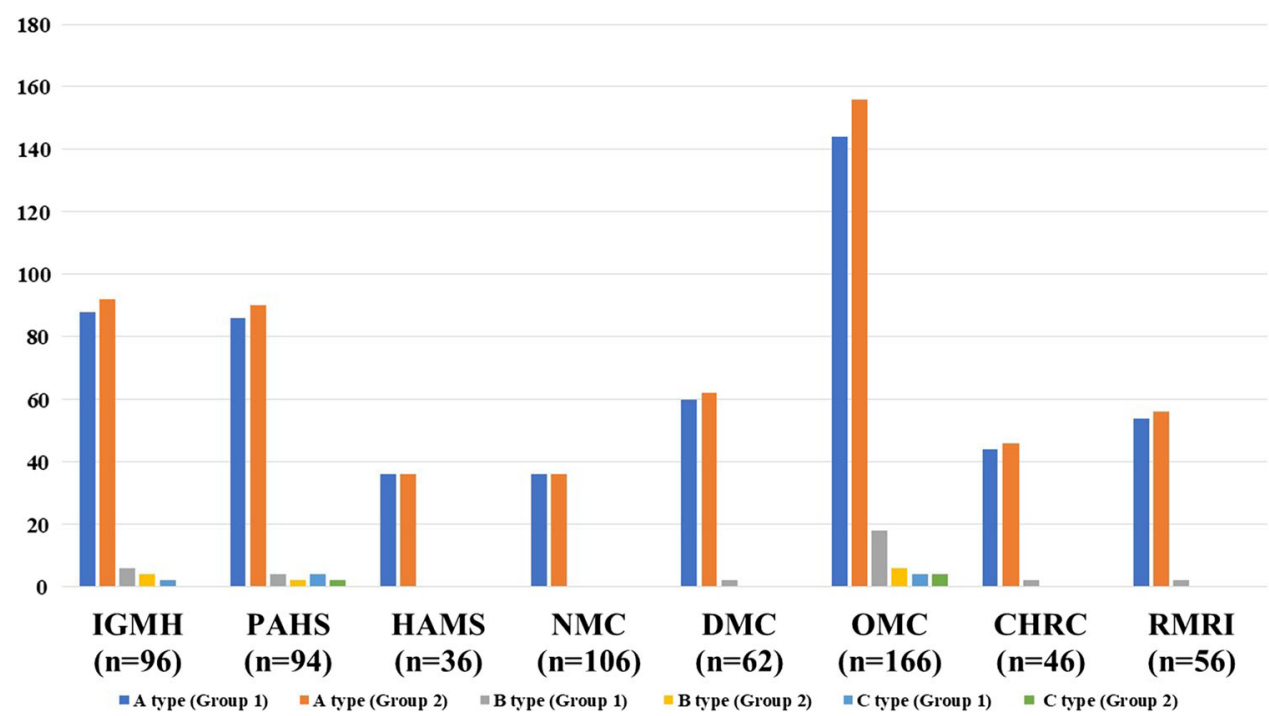

shown in Fig. 1. All the patients had these complaints in bilateral ears. There were no patients with recent onset ear discharge. Out of these aural symptoms, $7 / 62$ (11.2\%) of the patients mentioned these symptoms as their chief complain. The other 55/62 (88.8\%) patients talked about the presence of symptoms after being asked specifically about the aural symptoms. At 3 months follow up, none of the patients had persisting aural symptoms and there was no onset of any new symptoms.

The average $\mathrm{AC}$ and $\mathrm{BC}$ of group 1 and 2, along with that of the control group for low and high frequencies, is as shown in Figs. 2 and 3 respectively. There were 21/662 (3.2\%) ears of COVID-19 positive patients with mild conductive hearing loss, as per the World Health Organization (WHO) [24]. All of these ears were found to be having normal hearing at 3 months follow up. The difference of average $\mathrm{AC}$ and $\mathrm{BC}$ between group 1 and control group for low frequencies, by using an independent t-test, was not significant with $p$ values of 0.09 and 0.11 , respectively. Similarly, the difference of average AC and $\mathrm{BC}$ between group 1 and control group for high frequency was not significant with $p$ values of 0.1 and 0.08 , respectively. The difference of average $\mathrm{AC}$ and $\mathrm{BC}$ between group 2 and control group for low frequency was not significant with $p$ values of 0.07 and 0.08 , respectively. The difference of the average $\mathrm{AC}$ and $\mathrm{BC}$ between group II and control group for high frequency was not significant with $p$ values of 0.09 and 0.11 respectively.

The impedance audiometry of the COVID positive patients (Group 1 and 2) is as shown in Fig. 4. All the individuals in control group had A curve in bilateral ears. As can be seen in Fig. 4, there were 548/662 (82.8\%) and $556 / 662(83.9 \%)$ ears with A type curve, 34/662 (5.2\%) and $12 / 662(1.8 \%)$ ears with B type curve, 10/662 (1.5\%) and 6/662 (0.9\%) ears with $\mathrm{C}$ type curve, in group 1 and 2 respectively. There were no ears with As and Ad type curve. All the individuals in control group had A type curve in bilateral ear.

\section{Discussion}

The viral infections such as Cytomegalo virus, Rubella virus, Herpes simplex virus, Measles virus, Varicella zoster virus, Epstein Bar virus, Entero virus, Mumps virus, Chikungunya virus, and Human immune deficiency virus have been found to be associated with the hearing loss [17, 25-30]. The hearing loss caused by these viruses can be congenital or acquired, and can be either sensorineural or conductive or both [18]. COVID-19 is primarily the disease of the respiratory tract. The virus colonizes, and multiplies in the respiratory system, involving nasopharynx, trachea, bronchi, and then lungs producing multiple symptoms [31, 32]. The virus then involves multiple organ system of the body such as gastrointestinal system, nervous system, musculoskeletal system, and renal system [33-35].

The present study evaluates the impact of COVID-19 infection in the hearing status of the patients. For this study, the data collection was performed from multiple institutes, so that the geographical variations in the pathogenesis of COVID-19 can be well understood. Another aim of involving multiple institutes was to collect a greater sample size. All the institutes participating in the study were tertiary care centers, certified for the management of the COVID-19 patients. The control group was selected for comparison of the hearing status of the COVID-19 patients since it was felt that comparing with the normal subjects is always better than comparing with the normal value. The control group was selected by 
addressing the confounding factors of age, gender, and presence of any ear related diseases.

The COVID-19 patients and the control group included in the study were the ones with no history suggestive of any previous ear complain or ear disease. This was done to avoid any bias in the study since the detected hearing loss could be due to pre-existing condition rather than COVID19 infection. The age group for the inclusion in the study was set from 15 to 45 years. The lower limit of age was set at 15 years because with PTA being a subjective test there is always a chance of biased results in the child age group. The upper age limit was set to 45 years in order to avoid the age-related hearing loss based on studies in the literature which suggest the emergence of age related hearing from the 5th decade of life [36, 37]. Mustafa [23] in their study included the COVID-19 patients aged between 20 and 50 years, for the similar reasons. They performed PTA after 14 days of being confirmed of COVID-19 infection and compared with the control group. Besides PTA, the study by Mustafa [23] incorporated the impedance measurement and transient evoked otoacoustic emissions in their study. In contrast, the present study has evaluated patients only with PTA and impedance audiometry. The primary reason for this was to minimize the risk of COVID-19 transmission while carrying out multiple investigations. It was a difficult task to carry out all the evaluations at the participating institutes while taking the necessary COVID-19 precautions.

The COVID-19 patients were inquired in detail about the ear related symptoms, with duration of onset not more than 14 days. As duration of onset more than 14 days will signify pathology other than COVID-19 infection. The hearing evaluation and history taking was performed for the COVID-19 patients initially at the time when RT PCR was positive and after 3 months of the initial PTA. This was performed with an intention to find out both; the early as well as the late effect of COVID-19 infection on hearing mechanism and also the time duration for symptom resolution. The PTA was evaluated in the wide range of frequencies from 1000 to $8000 \mathrm{~Hz}$, to investigate the frequency levels most affected by the COVID-19 infection. The type of the tympanogram was evaluated in the present study to explore the probable impact of the COVID-19 infection in the middle ear. The patients undergoing any medications for COVID-19 infections were excluded from the study as the widely prescribed medicines for COVID19 such as Hydroxychloroquine, Azithromycin, Antiviral agents, antibiotics (cephalosporins, fluoroquinolones, penicillin's), Non-steroidal anti-inflammatory drugs, Angiotensin receptor blockers, and others are known to cause ototoxicity [38-40].

The present study demonstrated aural symptoms, such as tinnitus in $1.8 \%$, aural fullness in $11.4 \%$, hearing loss in
$3.9 \%$, and ear ache in $1.8 \%$ COVID-19 patients. However, only $11.2 \%$ complained about the presence of these symptoms. Thus, it can be inferred that the symptoms were not severe in most of the patients $(88.8 \%)$. The previous studies in the literature have not described about the aural symptoms in the COVID-19 patients [4, 16, 41, 42]. The presence of the aural symptoms can be corelated to the inflammation in the nasopharynx of the patients, resulting in deranged functioning of the eustachian tube. It is further supported by the fact that at 3 months follow up all of these symptoms were resolved.

This study demonstrated no significant change in the hearing status of the COVID-19 patients in comparison to the control group for all frequencies. The $3.2 \%$ patients had mild conductive hearing loss that got improved at 3 months follow, but it was not significant. The finding of mild conductive hearing loss was corelated with the nasopharyngeal inflammation due to COVID-19 infection. The presence or absence of the COVID-19 virus in the middle ear was not detected in present study. In contrast, Mustafa [23] in their study had shown a significant difference in the higher frequencies when compared to the control group. Further, Koumpa et al. [43], Chern et al. [22] and Abdel Rhman et al. [21] reported a case of sudden sensorineural hearing loss post COVID-19 infection. Elibo [44] in their study demonstrated sudden sensorineural hearing loss in $1 / 155(0.6 \%)$ and Özçelik Korkmazl et al. [1] demonstrated hearing loss in 6/116 (5.1\%) patients following COVID-19 infection respectively, though they have not mentioned about the type of hearing test performed for those patients.

The impedance audiometry demonstrated Type B tympanogram in $5.1 \%$ ears, out of these $64.7 \%$ improved at 3 months follow up. Type $\mathrm{C}$ curve was found in $1.1 \%$ of ears and got resolved in $40 \%$ at 3 months follow up. The $35.3 \%$ of the ears with type B curve and $60 \%$ with type C curve who did not improve at 3 months follow up were asymptomatic with normal PTA. Hence the pathology responsible for the B type curve in these patients could not be determined precisely, it could be either due to the COVID-19 infection or it could be due to any pathology other than the COVID infection. These patients were advised for follow up after 6 weeks for further evaluation.

The main challenge faced during the present study was to adopt the precautionary measures while performing the hearing assessment in COVID-19 positive patients. Utmost care was adopted during the PTA. The technician performing PTA was provided with full personal protective equipment (PPE) and the patients were provided with face mask and face shield. The ear plugs and PTA equipment were thoroughly cleaned with $80 \%$ ethanol following the procedure. 
Despite this study being unique and largest of its kind, few limitations were observed. The small sample size, inability to perform other audiological tests, and small duration of follow up were felt to be the limitations of the study. There is need for more research in this subject matter for proper understanding of the impact of COVID19 on hearing mechanism. A recommendation has been put forward for a future study with increased sample size and increased duration of follow up.

\section{Conclusion}

The COVID-19 infection may present with few aural symptoms; however, it was concluded that there was no significant difference in the hearing status of the COVID19 positive patients in comparison to the control group. The hearing status after 3 months of the COVID-19 infection also was not significantly different from the control group. The presence of some changes in the normal functioning of the eustachian tube and middle ear in the COVID-19 infection has also been highlighted. This study has also suggested for a future study with larger sample size and increased duration of the follow up for better understanding of the subject matter.

Acknowledgements This research was fully supported by the ENT department and the research department of the Indira Gandhi memorial hospital (IGMH) (Male', Maldives), Patan academy of health sciences (PAHS) (Patan, Nepal), Hospital for advanced medicine and surgery (HAMS) (Kathmandu, Nepal), Devdaha Medical college (DMC) (Butwal, Nepal), National Medical college (NMC) (Birgunj, Nepal), Osmania Medical college (OMC) (Hyderabad, India), Continental hospital and research center (CHRC) (Hyderabad, India) and Rajshree Medical Research Institute (RMRI) (Bareily, India). We would like to extend our heartful thanks to all our colleagues from ENT Department of these institutes who provided insight and expertise that greatly assisted the research. Few names to mention of special thanks, we would like to thank Dr Pallavi Sinha, head of research department (OMC), Dr Gayatri Yadav, head of research department (NMC), Dr Nina Pathak, head of research department (PAHS), Ahmed Khan, Ravi Ojha and Shweta Shrestha, research assistant, research Department of IGMH, DMC, and HAMS respectively, for their immense assistance in the biostatistics, language correction and technical issues.

\section{Declarations}

Conflict of interest The authors declare that they have no conflict of interest.

Ethical Approval This manuscript has been read and approved by all the authors and the requirements for authorship have been met. Each author approves that the manuscript represents original work.

\section{References}

1. Özçelik Korkmaz M, Eğilmez OK, Özçelik MA, Güven M (2020) Otolaryngological manifestations of hospitalised patients with confirmed COVID-19 infection. Eur Arch Oto-Rhino-Laryngol 1:3. https://doi.org/10.1007/s00405-020-06396-8

2. Lang B, Hintze J, Conlon B (2020) Coronavirus disease 2019 and sudden sensorineural hearing loss. J Laryngol Otol 134:1026-1028. https://doi.org/10.1017/S0022215120002145

3. Hassan SA, Sheikh FN, Jamal S et al (2020) Coronavirus (COVID-19): a review of clinical features, diagnosis, and treatment. Cureus. https://doi.org/10.7759/cureus. 7355

4. Mao L, Jin H, Wang M et al (2020) Neurologic manifestations of hospitalized patients with coronavirus disease 2019 in Wuhan, China. JAMA Neurol 77:683-690. https://doi.org/10.1001/ jamaneurol.2020.1127

5. Cucinotta D, Vanelli M (2020) WHO declares COVID-19 a pandemic. Acta Biomed 91:157-160

6. Bogoch II, Watts A, Thomas-Bachli A et al (2020) Potential for global spread of a novel coronavirus from China. J Travel Med 27:1-3. https://doi.org/10.1093/jtm/taaa011

7. Din A, Li Y, Khan T, Zaman G (2020) Mathematical analysis of spread and control of the novel corona virus (COVID-19) in China. Chaos Solitons Fract 141:110286. https://doi.org/10.1016/ j.chaos.2020.110286

8. Gandhi S, Bhatta S, Saindani SJ et al (2020) Safety Protocols for Videolaryngoscopy During the COVID-19 Pandemic: A Prospective Review of 196 Cases. Indian J Otolaryngol Head Neck Surg. https://doi.org/10.1007/s12070-020-02116-0

9. Gupta A, Madhavan MV, Sehgal K et al (2020) Extrapulmonary manifestations of COVID-19. Nat Med 26:1017-1032

10. Liu K, Fang YY, Deng Y et al (2020) Clinical characteristics of novel coronavirus cases in tertiary hospitals in Hubei Province. Chin Med J (Engl) 133:1025-1031. https://doi.org/10.1097/CM9. 0000000000000744

11. Guan W, Ni Z, Hu Y et al (2020) Clinical characteristics of 2019 novel coronavirus infection in China. $N$ Engl $J$ Med. https://doi.org/10.1101/2020.02.06.20020974

12. Liu K, Chen Y, Lin R, Han K (2020) Clinical features of COVID19 in elderly patients: a comparison with young and middle-aged patients. J Infect 80:e14-e18

13. He J, Guo Y, Mao R, Zhang J (2020) Proportion of asymptomatic coronavirus disease 2019: a systematic review and meta-analysis. J Med Virol. https://doi.org/10.1002/jmv.26326

14. Fang Z, Fi Y, Wu K, Characteristics C, of, et al (2019) Coronavirus pneumonia (COVID-19): an updated systematic review. MedRxiv. https://doi.org/10.1101/2020.03.07.20032573

15. Olfactory Dysfunction and Sinonasal Symptomatology in COVID-19: prevalence, severity, timing, and associated characteristics. https://www.ncbi.nlm.nih.gov/pmc/articles/PMC7240313/\#bibr60194599820929185. Accessed 4 Sep 2020

16. Bhatta S, Gandhi S, Saindani SJ et al (2021) Otorhinolaryngological manifestations of coronavirus disease 2019: a prospective review of 600 patients. J Laryngol Otol. https://doi.org/10.1017/ S0022215121000220

17. Liao BS, Byl FM, Adour KK (1992) Audiometric comparison of Lassa fever hearing loss and idiopathic sudden hearing loss: Evidence for viral cause. In: Otolaryngology-head and neck surgery. SAGE Publications, Los Angeles, pp 226-229

18. Cohen BE, Durstenfeld A, Roehm PC (2014) Viral causes of hearing loss: a review for hearing health professionals. Trends Hear 18:233121651454136. https://doi.org/10.1177/233121651 4541361 
19. Berrocal JRG, Ramírez-Camacho R, Portero F, Vargas JA (2000) Role of viral and Mycoplasma pneumoniae infection in idiopathic sudden sensorineural hearing loss. Acta Otolaryngol 120:835-839. https://doi.org/10.1080/000164800750061688

20. Wilson WR, Veltri RW, Laird N, Sprinkle PM (1983) Viral and epidemiologic studies of idiopathic sudden hearing loss. Otolaryngol Neck Surg 91:653-658. https://doi.org/10.1177/0194 59988309100612

21. Abdel Rhman S, Abdel Wahid A (2020) COVID -19 and sudden sensorineural hearing loss, a case report. Otolaryngol Case Reports 16:100198. https://doi.org/10.1016/j.xocr.2020.100198

22. Chern A, Famuyide AO, Moonis G, Lalwani AK (2021) Bilateral sudden sensorineural hearing loss and intralabyrinthine hemorrhage in a patient with COVID-19. Otol Neurotol 42:e10-e14. https://doi.org/10.1097/MAO.0000000000002860

23. Mustafa MWM (2020) Audiological profile of asymptomatic Covid-19 PCR-positive cases. Am J Otolaryngol Head Neck Med Surg 41:102483. https://doi.org/10.1016/j.amjoto.2020.102483

24. Humes LE (2019) The World Health Organization's hearingimpairment grading system: an evaluation for unaided communication in age-related hearing loss. Int J Audiol 58:12-20

25. Chau JK, Lin JRJ, Atashband S et al (2010) Systematic review of the evidence for the etiology of adult sudden sensorineural hearing loss. Laryngoscope. https://doi.org/10.1002/lary.20873

26. Gross M, Wolf DG, Elidan J, Eliashar R (2007) Enterovirus, cytomegalovirus, and Epstein-Barr virus infection screening in idiopathic sudden sensorineural hearing loss. Audiol Neurotol 12:179-182. https://doi.org/10.1159/000099021

27. Pitaro J, Bechor-Fellner A, Gavriel H et al (2016) Sudden sensorineural hearing loss in children: etiology, management, and outcome. Int J Pediatr Otorhinolaryngol 82:34-37. https://doi.org/ 10.1016/j.ijporl.2015.12.022

28. Bhavana K, Tyagi I, Kapila RK (2008) Chikungunya virus induced sudden sensorineural hearing loss. Int J Pediatr Otorhinolaryngol 72:257-259. https://doi.org/10.1016/j.ijporl.2007. 09.022

29. Chen H-C, Chung C-H, Wang C-H et al (2017) Increased risk of sudden sensorineural hearing loss in patients with hepatitis virus infection. PLoS ONE 12:e0175266. https://doi.org/10.1371/ journal.pone.0175266

30. Toubi E, Halas K, Ben-David J et al (2004) Immune-mediated disorders associated with idiopathic sudden sensorineural hearing loss. Ann Otol Rhinol Laryngol 113:445-449. https://doi.org/ 10.1177/000348940411300605

31. Barth RF, Buja LM, Parwani AV (2020) The spectrum of pathological findings in coronavirus disease (COVID-19) and the pathogenesis of SARS-CoV-2. Diagn Pathol 15:85

32. Kordzadeh-Kermani E, Khalili H, Karimzadeh I (2020) Pathogenesis, clinical manifestations and complications of coronavirus disease 2019 (COVID-19). Future Microbiol 15:1287-1305. https://doi.org/10.2217/fmb-2020-0110

33. Lodigiani C, Iapichino G, Carenzo L et al (2020) Venous and arterial thromboembolic complications in COVID-19 patients admitted to an academic hospital in Milan, Italy. Thromb Res 191:9-14. https://doi.org/10.1016/j.thromres.2020.04.024

34. Ruan Q, Yang K, Wang W et al (2020) Clinical predictors of mortality due to COVID-19 based on an analysis of data of 150 patients from Wuhan, China. Intensive Care Med 46:846-848

35. Li L, quan, Huang T, Wang Y qing, et al (2020) COVID-19 patients' clinical characteristics, discharge rate, and fatality rate of meta-analysis. J Med Virol 92:577-583

36. Huang Q, Tang J (2010) Age-related hearing loss or presbycusis. Eur Arch Oto-Rhino-Laryngol 267:1179-1191

37. Seidman MD, Ahmad N, Bai U (2002) Molecular mechanisms of age-related hearing loss. Ageing Res Rev 1:331-343

38. Simdon J, Watters D, Bartlett S, Connick E (2001) Ototoxicity associated with use of nucleoside analog reverse transcriptase inhibitors: a report of 3 possible cases and review of the literature. Clin Infect Dis 32:1623-1627. https://doi.org/10.1086/320522

39. Jung TTK, Rhee CK, Lee CS et al (1993) Ototoxicity of salicylate, nonsteroidal anti-inflammatory drugs, and quinine. Otolaryngol Clin N Am 26:791-810

40. Ciorba A, Corazzi V, Skarżyński PH et al (2020) Don't forget ototoxicity during the SARS-CoV-2 (Covid-19) pandemic! Int J Immunopathol Pharmacol 34:205873842094175. https://doi.org/ $10.1177 / 2058738420941754$

41. Wang D, Hu B, Hu C et al (2020) Clinical characteristics of 138 hospitalized patients with 2019 novel coronavirus-infected pneumonia in Wuhan, China. JAMA J Am Med Assoc 323:1061-1069. https://doi.org/10.1001/jama.2020.1585

42. Lechien JR, Chiesa-Estomba CM, De Siati DR et al (2020) Olfactory and gustatory dysfunctions as a clinical presentation of mild-to-moderate forms of the coronavirus disease (COVID-19): a multicenter European study. Eur Arch Oto-Rhino-Laryngol 277:13. https://doi.org/10.1007/s00405-020-05965-1

43. Koumpa FS, Forde CT, Manjaly JG (2020) Sudden irreversible hearing loss post COVID-19. BMJ Case Rep 13:238419. https://doi.org/10.1136/bcr-2020-238419

44. Elibol E (2020) Otolaryngological symptoms in COVID-19. Eur Arch Oto-Rhino-Laryngol 1:3. https://doi.org/10.1007/s00405020-06319-7

Publisher's Note Springer Nature remains neutral with regard to jurisdictional claims in published maps and institutional affiliations. 